\title{
Commentary: The superiority of noninferiority
}

\author{
Paul Kurlansky, MD
}

\author{
From the Division of Cardiac Surgery, Department of Surgery, Columbia University, New York, NY. \\ Disclosures: Author has nothing to disclose with regard to commercial support. \\ Received for publication March 16, 2019; accepted for publication March 18, 2019; available ahead of print April \\ $25,2019$. \\ Address for reprints: Paul Kurlansky, MD, Associate Professor of Surgery, Division of Cardiac Surgery, Columbia \\ University, Black Building 210, 650 W 168th St, New York, NY 10032 (E-mail: Pk2245@cumc.columbia.edu). \\ J Thorac Cardiovasc Surg 2020;159:1866-7 \\ $0022-5223 / \$ 36.00$ \\ Copyright (C) 2019 by The American Association for Thoracic Surgery \\ https://doi.org/10.1016/j.jtcvs.2019.03.077
}

Perhaps no topic has so captivated the cardiac surgical research imagination as the quest for the perfect method of myocardial preservation. Since the introduction of hypothermia ${ }^{1}$ and potassium, ${ }^{2}$ there has been extraordinary progress in the development of safe, reproducible, and readily applicable techniques and solutions. Recent interest has increased in single-dose approaches that facilitate the uninterrupted conduct of complex operations. ${ }^{3}$ Histidinetryptophan-ketoglutarate solution (Custodiol HTK; Essential Pharmaceuticals, LLC, Durham, NC), an intracellular cardioplegic solution developed largely for use in transplantation, ${ }^{4}$ has gained popularity as a potentially convenient single-dose approach to myocardial preservation in the absence robust randomized control data on effectiveness. ${ }^{5}$ Into this gap step Vivacqua and colleagues, ${ }^{6}$ with a noninferiority trial in this issue of the Journal comparing single-dose Custodiol HTK with repetitive cold blood cardioplegia. Vivacqua and colleagues ${ }^{6}$ are certainly to be congratulated - as difficult as it can be to conduct prospective, randomized, controlled trials in cardiac surgery, the noninferiority trial design introduces another layer of complexity.

Developed to evaluate new therapeutic approaches with similar clinical efficacy but other potential benefits, the noninferiority design is more complex than the more common superiority approach. The null hypothesis states that the experimental treatment is worse than that of the positive control by a prespecified margin, and noninferiority is demonstrated by rejection of that null hypothesis at a prespecified level of statistical significance. ${ }^{7}$ Selection of an appropriate margin is frequently guided by previous prospective, randomized, controlled trials of the active "control" versus placebo. The margin cannot be greater than the smallest effect size for the active treatment that could be expected from such a placebo-controlled trial. Unfortunately, there is no placebo-controlled study that could reasonably test use versus nonuse of cardioplegia. Vivacqua and colleagues, ${ }^{6}$ therefore determined their margin on the basis of a $50 \%$ difference in biomarkers. ${ }^{8}$ With these liberal margins of treatment effect, the study end point of

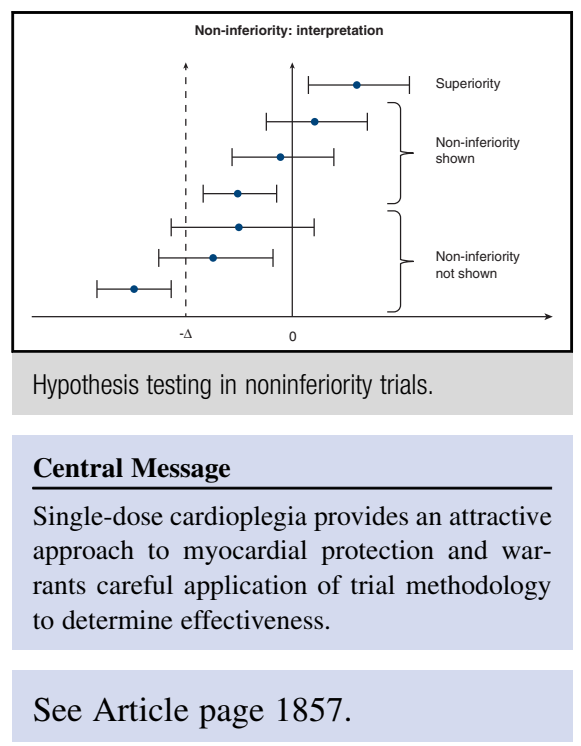

noninferiority was met. One is left, however, with a troubling question. If cardiac enzyme release is an accurate reflection of myocardial injury, are we really willing to accept a method that results in as much as $49 \%$ greater injury to the myocardium? If so, then their power calculation would support a test of noninferiority. Given the nature of cardiac surgical patients for whom we currently care, however, many with reduced ventricular function, myocardial hypertrophy, diabetic vasculopathy, and so on, if one would not accept such a wide margin of injury, then the study is not sufficiently powered. It is certainly true that the actual confidence intervals achieved suggest that a much tighter margin might have been met, but that would have required many more than 55 patients in each arm of the trial. Had the study been performed with a less generous margin, perhaps investigators would have been discovered that 1 in 100 patients has a fatal adverse reaction, or that there is some subset not sufficiently represented for whom this approach does not work well. Given the historical track record of this particular solution, such "random" adverse events do seem unlikely. Noninferior? Maybe. Maybe even probably. Careful application of experimental design will, I hope, inform future more definitive trials.

\section{References}

1. Bigelow WG, Lindsey WK, Greenwood WF. Hypothermia; its possible role in cardiac surgery: an investigation of factors governing survival in dogs at low body temperatures. Ann Surg. 1950;132:849-56.

2. Melrose DG, Dreyer B, Bentall HH, Baker JB. Elective cardiac arrest: preliminary communication. Lancet. 1955;2:21-2.

3. Nardi P, Pisano C, Bertoldo F, Guvolo G. New insights on the use of del Nido cardioplegia in the adult cardiac surgery. J Thorac Dis. 2018;10(Suppl 26):S3233-6. 
4. Hachida M, Ookado A, Nonoyama M, Koyanagi H. Effect of HTK solution for myocardial preservation. J Cardiovasc Surg. 1996;37: 269-74.

5. Edelman JJB, Seco M, Dunne B, Matzelle SJ, Murphy M, Joshi P, et al. Custodiol for myocardial protection and preservation: a systematic review. Ann Cardiothorac Surg. 2013;2:717-28.

6. Vivacqua A, Robinson J, Abbas AE, Altschuler JM, Shannon FL, Podolsky RH, et al. Single-dose cardioplegia protects myocardium as well as traditional repetitive dosing: a noninferiority randomized study. J Thorac Cardiovasc Surg. 2020;159:1857-63.e1.

7. Mauri L, D'Agostino RB Sr. Challenges in the design and interpretation of noninferiority trials. $N$ Engl J Med. 2017;377:1357-67.

8. Braathen B, Jeppsson A, Scherstén H, Hagen OM, Vengen O, Rexius H, et al. One single dose of histidine-tryptophan-ketoglutarate solution gives equally good myocardial protection in elective mitral valve surgery as repetitive cold blood cardioplegia: a prospective randomized study. J Thorac Cardiovasc Surg. 2011;141:995-1001. 